\title{
Rooting and Establishment of Bunchberry Stem Cuttings as Affected by Propagation Date, K-IBA, Rooting Duration, and by Division or Cuttage
}

\author{
Janine G. Haynes ${ }^{1}$ and John M. Smagula ${ }^{2}$ \\ Horticulture Program, Department of Biosystems Science and Engineering, \\ University of Maine, Orono, Maine 04469-5722
}

Paul E. Cappiello

Horticulture Director, Bernheim Arboretum and Research Forest, Clermont, KY 40110-0130

Additional index words. Cornus canadensis, rhizome, auxin-inhibition, lateral buds, cutting length, groundcover, dwarf cornel, Chamaepericlymenum canadense

\begin{abstract}
Stem cuttings were harvested in April from four clones of containerized bunchberry (Cornus canadensis L.) forced in the greenhouse and in June from the same four clones growing in the field. April cuttings that had produced rhizomes by transplant time produced the greatest mean number and weight of shoots during the first growing season compared to April cuttings without rhizomes, June cuttings with rhizomes, or June cuttings without rhizomes. In a second study, cuttings and single-stem divisions were taken in July; divisions produced a greater mean number of shoots than did stem cuttings when compared at the end of Oct. A third study evaluated the effect of K-IBA application to lateral buds on subsequent rhizome production, and the effect of cutting node number (two vs. three nodes) on root or rhizome development. Treating lateral buds with K-IBA was not inhibitory to rhizome formation and elongation. Compared to two-node cuttings, three-node cuttings produced greater mean rootball size, rhizome number, and rhizome length; nearly twice as many of the three-node cuttings formed rhizomes as did two-node cuttings. A fourth study showed that cuttings rooted for 5 or 6 weeks in a mist enclosure generally exhibited greater shoot and rhizome production by the end of the first growing season than cuttings rooted for 8 or 9 weeks. This was despite the finding that cuttings rooted for longer durations ( 8 or 9 weeks) possessed larger rootballs and greater rhizome numbers at transplant time compared to cuttings rooted for shorter durations (5 to 6 weeks). Chemical name used: indole-3-butyric acid (K-IBA).
\end{abstract}

Bunchberry (Cornus canadensis L.) is a native perennial groundcover that grows in the northern latitudes of North America and Asia. It is commonly found growing in the forest understory, in open fields, and on hummocks in bogs of New England (Dirr, 1990). Bunchberry is a secondary successional plant (Alaback, 1984) and commonly colonizes the open fields where commercial lowbush blueberries are grown; as such it has become a serious weed in some areas of Maine and Canada (Hall and Sibley, 1976).

Bunchberry has many characteristics that make it suitable for use as an ornamental groundcover. Bunchberry spreads laterally by rhizomes which can extend up to $30 \mathrm{~cm}$ per year (Hall and Sibley, 1976) forming a dense mat of foliage. These rhizomes are perennial

\footnotetext{
Received for publication 20 July 2001. Accepted for publication 11 Apr. 2002. This research was supported by funds provided by the Maine Agricultural and Forest Experiment Station under provision of the Hatch Act. MAFES contribution No. 2542. Mention of trade names does not imply endorsement of the products or companies named.

${ }^{1}$ Former graduate research assistant.

${ }^{2}$ Professor. To whom reprint requests should be addressed. E-mail address: smagula@maine.edu
}

and allow the plant to overwinter and produce new growth the following spring. Stems range from 5 to $20 \mathrm{~cm}$ in length and bear a terminal whorl of four or six leaves with one or more sub-terminal nodes bearing reduced leaves and axillary buds. The stems bear inflorescences subtended by showy white bracts in spring and early summer, clusters of bright red fruit in late summer, and the foliage turns burgundy in autumn.

Despite the potential for more extensive use of this plant in northern landscapes, little research has been conducted concerning methods for its propagation or production. Bunchberry has traditionally been propagated by seed, division, or transplanting sod pieces taken from the field (Dirr, 1990). Seeds require warm stratification followed by cold stratification or scarification followed by cold stratification to germinate in reasonable percentages (Dirr and Heuser, 1987). Witt (1987) described propagation of bunchberry from divisions consisting of a rhizome and 3 to 5 shoots, prepared in September and overwintered under protective glass until May. Stem cuttings stuck in May without rooting hormones rooted in 4-6 weeks under fog.

Haynes et al. (1998) treated bunchberry cuttings with six concentrations of K-IBA $\left(0,1000,3000,5000,7000\right.$, or $9000 \mathrm{mg} \cdot \mathrm{L}^{-1}$ $\mathrm{K}$-IBA in water) and found that after 10 weeks in a humidity tunnel, rooting percentage was unaffected by K-IBA application. However, rootball size was greatest when cuttings were treated with 3000 or $7000 \mathrm{mg} \cdot \mathrm{L}^{-1} \mathrm{~K}$-IBA. Cuttings treated with 7000 or $9000 \mathrm{mg} \cdot \mathrm{L}^{-1}$ $\mathrm{K}$-IBA produced fewer rhizomes than cuttings treated with 0 or $1000 \mathrm{mg} \cdot \mathrm{L}^{-1} \mathrm{~K}$-IBA. Cuttings treated with K-IBA concentrations ranging from 0 to $5000 \mathrm{mg} \cdot \mathrm{L}^{-1}$ were statistically similar in the number and length of rhizomes produced during rooting. Based on these results, a concentration of $3000 \mathrm{mg} \cdot \mathrm{L}^{-1} \mathrm{~K}$-IBA was recommended to optimize both root and rhizome development on bunchberry cuttings (Haynes et al., 1998).

The purpose of this work was to devise a system for successful propagation of bunchberry from stem cuttings in a nursery setting. Four factors were studied: 1) date of propagation; 2) stem cuttings vs. divisions (the traditional method of propagation); 3 ) node numbers and the effect of potassium salt of K-IBA; and 4) duration of the rooting phase.

\section{Materials and Methods}

Propagation date. Cutting material was obtained from four bunchberry clones growing in lowbush blueberry fields: two in Ellsworth, Maine (clones A and B) and two in Jonesboro, Maine (clones C and D). All clones were growing in full sun in a Colton gravely loamy sand soil with a thin $(\approx 1.5 \mathrm{~cm})$ organic layer. Clones were chosen in Oct. 1996 on the basis of shoot uniformity and clear separation from nearby clones; portions of each clone were harvested as sod pieces, placed in eight flats $(10 \times 50.8 \times 38.1$ $\mathrm{cm}$ ), and kept outside until 10 Nov. The sod pieces were then overwintered in cold storage $\left(92 \mathrm{~d}\right.$ in the dark at $2.8^{\circ} \mathrm{C}$ ) and subsequently moved into a heated greenhouse $\left(18^{\circ} \mathrm{C}\right.$, ambient photoperiod of $\approx 9 \mathrm{~h}$ ) on $10 \mathrm{Feb}$. 1997 . The sod pieces were irrigated as needed and 300 ppm N soluble fertilizer $(20 \mathrm{~N}-8.7 \mathrm{P}-16.6 \mathrm{~K}$; Peter's General Purpose 20-20-20, Scotts-Sierra Horticultural Products Co., Marysville, Ohio) was applied weekly after new shoots emerged in Mar. 1997. Cuttings were taken from this greenhouse-forced material on 10 Apr. 1997 and from the same four clones in the field on 10 June 1997. Care was taken to avoid treating the first set of lateral buds (those of the first sub-terminal node) with K-IBA, by submerging the stem in K-IBA solution to a level below the first sub-terminal node. Cuttings on both dates were dipped in $3000 \mathrm{mg} \cdot \mathrm{L}^{-1}$ $\mathrm{K}$-IBA to the second node for $7 \mathrm{~s}$, allowed to air dry, and stuck into 1 peat : 3 perlite (by volume) in $40 \times 40 \times 12.7 \mathrm{~cm}$ polyethylene rooting flats (Anderson Die and Mfg. Co., Portland, Ore.). Cuttings were stuck to a depth such that the first node below the terminal whorl was $\approx 1 \mathrm{~cm}$ below the surface of the medium, since rhizomes arising from rooted cuttings generally originate from the axillary buds of the sub-terminal nodes. Flats were placed in a shaded polyethylene enclosure (irradiance level $120-250 \mu \mathrm{mol} \cdot \mathrm{m}^{-2} \cdot \mathrm{s}^{-1}$ ) and 
a mist emitter (Floodjet TK-VS10, Spraying Systems, Wheaton, Ill., $324 \mathrm{KPa}$ ) at one end of the enclosure propelled a fine mist over the cuttings (45 s every $10 \mathrm{~min}$ ) between sunrise and sunset. On 10 June and 8 Aug. (April and June propagation dates, respectively; rooting duration 9 weeks), rooting flats were removed from the mist enclosure and placed under $60 \%$ shade cloth. On 20 June and 16 Aug., for the April and June propagation dates respectively, cuttings were removed from the flats and evaluated for rootball dimensions and the presence of rhizomes.

Because there was variation in the extent of root and rhizome development among cuttings, rooted cuttings were categorized according to rootball size and the presence of rhizomes (Table 1) prior to transplanting. The effect of these differences on growth and spread was included as a variable in the study. The experiment was blocked by clone, and used a randomized complete-block design with a total of four replicate blocks. Within each block, cuttings were arranged in a 2 (propagation date) $\times 4$ (cutting class) complete factorial, with five cuttings per propagation date and cutting class combination. Cuttings were planted into 1 peat : 1 perlite (by volume) in $9.05 \times$ $9.05 \times 10.8 \mathrm{~cm}$ black band pots contained in 40 $\times 40 \times 12.7 \mathrm{~cm}$ flats (Anderson Die and Mfg. Co., Portland, Ore.). The $\mathrm{pH}$ of the medium ranged from 3.8 to 4.0. Cuttings were grown in a shaded greenhouse (40\% shade cloth, 580 to $1000 \mu \mathrm{mol} \cdot \mathrm{m}^{-2} \cdot \mathrm{s}^{-1}, 28$ to $35^{\circ} \mathrm{C}$ day $/ 15$ to $18^{\circ} \mathrm{C}$ night) and fertilized twice weekly with 300 ppm N (20N-8.7P-16.6K; Peters General Purpose 20-20-20, 16:1, Scotts Brass Siphon Mixer, Scotts). Fertilization continued until 19 Sept. when the plants were rated for number of shoots, foliar discoloration, and foliar necrosis. Foliar damage (necrosis and discoloration) was rated on a scale of 1 to 5 , with those rated 1 exhibiting little to no damage $(0 \%$ to $20 \%$ of the foliage), those rated 2,3 , or 4 exhibiting moderate damage $(21 \%$ to $40 \%, 41 \%$ to $60 \%$, and $61 \%$ to $80 \%$, respectively), and those rated 5 exhibiting severe damage $(81 \%$ to $100 \%$ of the foliage). In October, the flats were moved outside to acclimate under natural daylength and temperature. The bunchberry plants exhibited fall color and the aboveground portions of the plants desiccated with the leaves still attached. In November, flats were placed in an unheated greenhouse and stored until shoots could be collected for determination of total number of shoots and shoot dry weight. In February, shoots were counted and removed from each pot by clipping them off at the surface of the growth medium. Shoots were placed into paper bags, stored in a drying room $\left(42{ }^{\circ} \mathrm{C}\right)$ for a minimum period of 3 weeks, then weighed. Data were subjected to analysis of variance (ANOVA) using the general linear model of SAS (release 6.07, SAS Institute, Cary, N.C., 1992) and treatment means were separated using the Fisher's least significant difference test (LSD) $(P \leq 0.05)$. Shoot number data were subjected to square root transformation before being subjected to analysis.

Cutting vs. division propagation. Cuttings and single-stem divisions were taken from the four clones (A to D) collected in the field and overwintered in flats as described in the previous study. After Apr. cuttings were taken for the previous study, the containerized sod pieces were irrigated regularly and a second flush of growth was produced by the rhizomes. Cuttings and single-stem divisions were harvested from these plants on 13 July 1997. Cuttings were placed under intermittent mist for 8 weeks, removed on 4 Sept., and kept under shade for 1 week as described in the previous study. From each block, 24 rooted cuttings bearing one or more rhizomes were transplanted into 1 peat : 1 perlite (by volume) contained in band pots as described above. Rooted cuttings were fertilized twice weekly (20N-8.7P-16.6K, 300 ppm N, Peters General Purpose 20-20-20 Soluble Fertilizer) until 29 Sept. then moved outside.

Divisions were prepared as follows: sections of each sod piece were removed, roots and rhizomes were washed until most of the soil was removed, and aerial stems bearing both roots and healthy rhizomes were severed from the sod piece. Each single-stem division bore one or two rhizome fragments and a viable root system. Twenty-four divisions from each block were immediately transplanted into 1 peat : 1 perlite (by volume) contained in black band pots as described above. They were kept under intermittent mist for 3 weeks, allowing the roots to become established, then moved to a greenhouse bench. Plants were fertilized as above and on 29 Sept. they were moved outside. This study was blocked by clone and used a randomized complete-block design with four replicated blocks. Shoot number and dry weight were determined in Feb. 1998 as described previously. Data were subjected to ANOVAusing the general linear model of SAS and treatment means were separated using the Fisher's LSD test $(P \leq 0.05)$. Shoot number data were subjected to square root transformation before analysis.

Node number and lateral bud IBA application. To test the effect of sub-terminal node number and K-IBA treatment on root and rhizome formation, cuttings with two nodes (including the terminal node) and three nodes were taken from three different clones chosen from the previously described lowbush blueberry field in Ellsworth, Maine (designated clones E, F, and G). On 1 July 1997, 60 twonode and 60 three-node cuttings were taken from each clone.

Those in the first treatment group were dipped into $3000 \mathrm{mg} \cdot \mathrm{L}^{-1} \mathrm{~K}$-IBA to a level such that the lateral buds of the first sub-terminal node were submerged in the solution. The cuttings were treated for $7 \mathrm{~s}$, allowed to air-dry, and then stuck into 1 peat: 3 perlite (by volume) contained in rooting flats like those described above. Cuttings in the second treatment group were dipped into $3000 \mathrm{mg} \cdot \mathrm{L}^{-1} \mathrm{~K}$-IBA to a level below the first sub-terminal node, so the lateral buds were not exposed to the auxin. These cuttings were allowed to root in the mist enclosure described above until 3 Sept. 1997 when they were removed and placed under $60 \%$ shade cloth. On 10 Sept., the rooted cuttings were removed and assessed for root and rhizome formation. Data were subjected to a Chisquare test and it was found that node number and K-IBA treatment independently affected the number of rhizomes produced $(P=0.604)$. Data were then subjected to ANOVA and treatment means were separated by Fisher's LSD test $(P \leq 0.05)$.

Clone $\times$ rooting duration. This study was designed to account for clonal variation by using a completely random design with a complete factorial treatment arrangement: four cuttings sources (genetically distinct clones) and five rooting duration periods $(5$, $6,7,8$, or 9 weeks in the mist enclosure). Three of the four original clones used in the 1997 studies (A to C) were lost following mowing of the field, so three new clones $(\mathrm{H}, \mathrm{I}$, and $\mathrm{J})$

Table 1. Number of shoots, total shoot dry weight, and mean shoot dry weight of bunchberry plants grown from rooted cuttings as affected by propagation date and cutting class.

\begin{tabular}{|c|c|c|c|c|c|c|}
\hline \multirow[b]{2}{*}{ Cutting class } & \multicolumn{3}{|c|}{ April propagation date ${ }^{z}$} & \multicolumn{3}{|c|}{ June propagation date ${ }^{y}$} \\
\hline & No. shoots & $\begin{array}{l}\text { Total shoot } \\
\text { dry wt }(g)^{x}\end{array}$ & $\begin{array}{l}\text { Mean shoot } \\
\text { dry wt }(g)^{w}\end{array}$ & No. shoots $(\mathrm{g})$ & $\begin{array}{l}\text { Total shoot } \\
\text { dry wt }(g)^{x}\end{array}$ & $\begin{array}{c}\text { Mean shoot } \\
\text { dry } w^{w}\end{array}$ \\
\hline 1 Extensive root systems ${ }^{v}$, above-ground rhizomes & $8.15 \mathrm{a}^{\mathrm{u}, \mathrm{t}}$ & $1.75 \mathrm{a}$ & $0.21 \mathrm{a}$ & $2.80 \mathrm{a}^{\mathrm{u}, \mathrm{t}}$ & $0.52 \mathrm{a}$ & $0.19 \mathrm{a}$ \\
\hline 2 Extensive root systems, below-ground rhizomes & $8.30 \mathrm{a}$ & $1.68 \mathrm{a}$ & $0.21 \mathrm{a}$ & $3.10 \mathrm{a}$ & $0.48 \mathrm{a}$ & $0.15 \mathrm{a}$ \\
\hline 3 Extensive root systems, no rhizomes & $3.70 \mathrm{~b}$ & $0.59 \mathrm{~b}$ & $0.17 \mathrm{ab}$ & $1.25 \mathrm{~b}$ & $0.23 \mathrm{~b}$ & $0.20 \mathrm{a}$ \\
\hline 4 Poor root systems ${ }^{\mathrm{s}}$, no rhizomes & $2.35 \mathrm{~b}$ & $0.37 \mathrm{~b}$ & $0.12 \mathrm{~b}$ & $0.85 \mathrm{~b}$ & $0.18 \mathrm{c}$ & $0.13 \mathrm{a}$ \\
\hline
\end{tabular}

${ }^{2}$ Cuttings were stuck on 10 Apr. 1997, harvested 12 Feb. 1998.

${ }^{y}$ Cuttings were stuck on 10 June 1997, harvested 12 Feb. 1998.

${ }^{\mathrm{x}}$ Total dry weight of all shoots in a pot.

wAverage dry weight per shoot. Total shoot dry weight per pot/total number of shoots per pot.

vDefined as root ball size (length $\times$ width) $>10 \mathrm{~cm}^{2}$

"All values are means of four blocks; $\mathrm{n}=20$.

'Mean separation within propagation dates and columns by Fisher's protected LSD, $P \leq 0.05$.

${ }^{\mathrm{s}}$ Defined as root ball size (length $\times$ width) $<10 \mathrm{~cm}^{2}$ 
growing in Jonesboro, Maine were chosen for this study. On 25 June 1998, two hundred and twenty-five cuttings were taken from each of the four clones. Cuttings from each clone were randomly assigned to five treatment groups, with 45 cuttings per treatment. All cuttings were treated with $3000 \mathrm{mg} \cdot \mathrm{L}^{-1} \mathrm{~K}$-IBA for $7 \mathrm{~s}$ and allowed to air dry before sticking. Each treatment group was then divided into three sets of 15 cuttings each. Three individual flats were used for each rooting duration treatment, with each flat containing a row of cuttings from each clone, giving three replications of 15 cuttings for each treatment. These flats were randomly distributed within the mist enclosure and rearranged twice weekly throughout the study to minimize the effect of proximity to the mist emitter. Three flats were removed from the mist enclosure each week, beginning five weeks after sticking. Flats were then placed under $60 \%$ shade cloth and watered frequently for one week. Cuttings were removed from the rooting flats and assessed for percent rooting, rootball dimensions (measured as rootball length $x$ width), and number and length of rhizomes. These data were subjected to ANOVA and trend analysis $(P \leq 0.05)$ to determine overall response to the treatments. Following this evaluation (before-transplanting assessment), thirteen randomly selected rooted cuttings per clone were transplanted into 1 peat : 1 perlite (by volume) contained in black band pots as described above. These steps were repeated at each removal time. The plants were grown in the greenhouse $\left(28\right.$ to $35^{\circ} \mathrm{C} \mathrm{d} / 15$ to $18^{\circ} \mathrm{C}$ night, ambient photoperiod) and watered as needed until 27 Oct. Plants were then destructively sampled and assessed for rootball size, total number of shoots, rhizome number, total rhizome length, and total shoot and rhizome dry weight (Oct. assessment). These data were subjected toANOVAand treatment means were separated by Duncan's multiple range test $(P$ $\leq 0.05$ ). Pearson correlation coefficients were determined between dependent variables.

\section{Results and Discussion}

Propagation date. Date of propagation and rhizome presence (cutting class 1 to 4 ) affected number of shoots and shoot weight produced by bunchberry cuttings. Cuttings taken in Apr. and June produced an average of 5.62 and 2.00 shoots $(P \leq 0.001$, respectively. For both propagation dates, cuttings in classes 1 and 2 (those having rhizomes at transplant time) produced more than twice as many shoots by the end of the first season as did those in class 3 and three times as many as those in class 4 (Table 1). Similar trends were found for total shoot dry weight and mean shoot dry weight.

Cutting vs. division propagation. Plants started from divisions produced nearly twice as many shoots and a greater total shoot dry weight compared to plants started from cuttings (Table 2). Plants started from cuttings had a greater average shoot weight (Table 2). Number of shoots was relatively low for both propagation methods, possibly due to the short growing season available to the plants following propagation.
Node number and lateral bud IBA application. Percent rooting was unaffected by node number or K-IBA application and ranged from $88 \%$ to $95 \%$. K-IBA application (first set of lateral buds treated vs. buds untreated) had no effect on rootball size ( 28.71 vs. 26.46 $\mathrm{cm}^{2}$ ), number of rhizomes ( $0.36 \mathrm{vs}$. 0.31$)$, or rhizome length $(0.93$ vs. $0.91 \mathrm{~cm})$. Of the 62 three-node cuttings that produced rhizomes, 18 cuttings produced rhizomes at the first sub-terminal node, 36 produced rhizomes at the second sub-terminal node, and eight produced rhizomes at both nodes. Since buds of the second sub-terminal node were exposed to auxin regardless of treatment (only the buds of the first sub-terminal node were excluded from the K-IBA solution for the untreated group), it is clear that exogenous auxin application does not inhibit rhizome formation.

The number of sub-terminal nodes on the cutting affected rootball size, number of rhizomes, number of cuttings producing rhizomes, and length of rhizomes (Table 3). Of the 180 three-node cuttings stuck, 62 formed rhizomes by transplant time; only 34 of the 180 two-node cuttings produced rhizomes by transplant time. Cuttings with three nodes also produced slightly larger root systems and but more than twice the number of rhizomes compared with those cuttings having two nodes. Of cuttings that produced rhizomes, the mean rhizome length produced by three-node cuttings was more than twice that produced by two-node cuttings.

Three-node cuttings generally had longer stems than two-node cuttings; this could account for the slightly larger rootball size of the former, since cuttings with longer stems have greater stem surface area for production of adventitious roots. Rhizome number was likely greater in three-node than in two-node cuttings because the former had a greater number of lateral buds, and therefore a greater potential for producing rhizomes. Three-node cuttings were twice as likely to form rhizomes by the time of transplant than were two-node cuttings (Table 3).

Clone $\times$ rooting duration. Since there were marked differences among clones, the results for each clone are presented individually; an overall response derived by averaging treatment effects across the clones is also included to show the overall trend observed (Table 4).

Clone $\mathrm{H}$ showed a marked linear response to rooting duration with rootball size, rhizome number, and rhizome length increasing with increasing time up to 9 weeks in the mist enclosure (Table 4). Clone D showed a quadratic response for rootball size and rhizome number, with both reaching a maximum after 7 weeks in the mist enclosure. Rhizome length showed a positive linear response to increasing rooting duration for the entire 9 weeks (Table 4). Rootball size for clone I increased linearly with increasing rooting duration, with cuttings reaching highest rootball size after 9 weeks in the mist enclosure. Average rhizome length increased slightly with rooting duration but rhizome number was unaffected (Table 4). Cuttings from clone $\mathrm{J}$ also showed a linear response to rooting duration for rootball size and rhizome length but rhizome number was unaffected (Table 4).

Cuttings from clone $\mathrm{H}$ produced a significantly larger rootball size and greater rhizome number and length than cuttings from the other three clones (Table 4). Conversely, cuttings from clone I performed the poorest, producing the smallest rootball size and low rhizome number and length (Table 4). Clones J and D were intermediate in their responses; clone $\mathrm{J}$ produced a larger root mass but very few

Table 2. Number of shoots, total shoot dry weight, and mean shoot dry weight of bunchberry plants as affected by propagation method.

\begin{tabular}{|c|c|c|c|}
\hline Propagation method & $\begin{array}{l}\text { No. of } \\
\text { shoots }^{2}\end{array}$ & $\begin{array}{l}\text { Total shoot } \\
\text { dry wt }(g)^{z}\end{array}$ & $\begin{array}{l}\text { Mean shoot } \\
\text { dry wt }(g)^{z, y}\end{array}$ \\
\hline Stem cuttings ${ }^{x}$ & $1.24 \mathrm{~b}^{\mathrm{w}}$ & $0.20 \mathrm{~b}$ & $0.17 \mathrm{a}$ \\
\hline Single-stem divisions $^{v}$ & $2.15 \mathrm{a}$ & $0.27 \mathrm{a}$ & $0.13 \mathrm{~b}$ \\
\hline 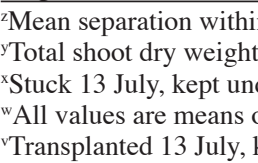 & $\begin{array}{l}\text { ns by Fis } \\
\text { / total nu } \\
8 \text { weeks, } \\
\text { locks; } 24 \\
\text { ler mist } 3\end{array}$ & $\begin{array}{l}\text { rotected LSD, } \\
\text { of shoots per } \\
\text { in greenhou } \\
\text { gs or divisior } \\
\text {, grown in g. }\end{array}$ & $\begin{array}{l}.05 . \\
\text { veeks. } \\
\text { block. } \\
\text { ouse } 9 \text { week }\end{array}$ \\
\hline
\end{tabular}

Table 3. Mean rootball size, mean number of rhizomes, number of cuttings producing rhizomes, and mean rhizome length as affected by bunchberry cutting node number. ${ }^{2}$

\begin{tabular}{lcccc}
\hline $\begin{array}{l}\text { No. of } \\
\text { nodes per } \\
\text { cutting }\end{array}$ & $\begin{array}{c}\text { Mean } \\
\text { root-ball } \\
\text { size }^{\mathrm{y}, \mathrm{x}}\left(\mathrm{cm}^{2}\right)\end{array}$ & $\begin{array}{c}\text { Mean } \\
\text { no of } \\
\text { rhizomes }^{\mathrm{y}}\end{array}$ & $\begin{array}{c}\text { No. of } \\
\text { cuttings producing } \\
\text { rhizomes }(\mathrm{cm})\end{array}$ & $\begin{array}{c}\text { Mean } \\
\text { rhizome } \\
\text { length }\end{array}$ \\
\hline 2 & $25.85 \mathrm{~b}^{\mathrm{v}}$ & $0.19 \mathrm{~b}^{\mathrm{v}}$ & $34 \mathrm{~b}^{\mathrm{u}}$ & $2.58 \mathrm{~b}^{\mathrm{v}}$ \\
3 & $29.47 \mathrm{a}$ & $0.49 \mathrm{a}$ & $62 \mathrm{a}$ & $5.55 \mathrm{a}$ \\
\hline
\end{tabular}

${ }^{2}$ Cuttings stuck 1 July 1997, data taken after 9 weeks.

${ }^{y}$ All values are means of three blocks; 60 cuttings per block.

${ }^{x}$ Values represent root mass width at the widest point $\times$ the greatest length measurement.

${ }^{\mathrm{w}}$ Mean of cuttings that produced rhizomes; two nodes, $\mathrm{n}=34$; three nodes, $\mathrm{n}=$ 62 .

'Mean separation within columns by Fisher's protected LSD, $P \leq 0.05$.

"Data analyzed using Chi-square test, $P \leq 0.05$. 
rhizomes while clone D produced a smaller root mass and a greater number of rhizomes (Table 4).

When assessed on 27 Oct. 1998, the mean number of shoots decreased with increasing rooting duration for clones $\mathrm{D}$ and $\mathrm{J}$ (Table 5). Cuttings from clone I showed a slight $(P$ $\leq 0.03$ ) positive linear increase in number of shoots with longer duration and clone $\mathrm{H}$ cuttings were unaffected. Rhizome production was not affected by rooting duration, except for clone $\mathrm{D}$, which exhibited a decrease in mean rhizome number from $\approx 5$ after 5 or 6 weeks to $\approx 1.5$ after 8 or 9 weeks. The mean number of rhizomes averaged across all rooting durations for clones $\mathrm{H}$, I, and $\mathrm{J}$ were $3.4,0.28$, and 0.97 , respectively.

Rhizome length and total shoot dry weight were unaffected by rooting duration (data not shown), but were significantly affected by clone (Table 6). Cuttings from clone $\mathrm{H}$ produced nearly twice the rhizome length as those from clone $\mathrm{D}$, three times the rhizome length as those from clone J, and 14 times the rhizome length as those from clone I. Total shoot weight followed a similar trend; clone $\mathrm{H}$ produced the highest total shoot massg while clone I produced the lowest total shoot mass.

Rootball size and rhizome weight per cutting were affected independently by clone and by rooting duration. Rootball sizes were greatest for plants from clones $\mathrm{H}$ and D (Table 6). Clone Hcuttings produced the greatest rhizome weight per cutting. Similar to the assessment before transplant, cuttings from clone I performed poorly, producing the lowest mean rootball size while clone J produced the lowest rhizome weight per cutting (Table 6).

Cutting rootball sizes were higher for cuttings in the 7-week rooting duration treatment than those from any other treatment (Table 7). Cuttings in the 9-week rooting duration treatment produced the greatest rhizome dry weight per cutting, though this weight was not significantly different than that for the 5- or 8-week treatments (Table 7). Average weight of each rhizome (total rhizome weight/rhizome number) was affected only by rooting duration and generally increased with increasing rooting duration (Table 7).

Correlation analysis was done on the dependent variables. Number of shoots was positively correlated with rhizome number $(r=$ 0.774 ) and also correlated with rhizome length $(r=0.490)$; this is important since rhizome production in the other studies was estimated by taking shoot counts. There was also a strong positive correlation between rootball size and shoot weight $(r=0.762)$, though only weak correlations existed between rootball size and number of shoots $(r=0.283)$, rhizome number $(r=0.365)$, and rhizome length ( $r=$ $0.355)$. This indicates that while formation of large root systems may have a positive effect on shoot weight, it might not be predictive of increased rhizome growth and spread following rooting.

The results of this study show that there was a great deal of variation among clones in root and rhizome formation. Clone I consistently performed poorly for all response

Table 4. Mean root area, rhizome number, and rhizome length of bunchberry rooted cuttings as affected by rooting duration and clone (assessment before transplanting $)^{\mathrm{z}}$

\begin{tabular}{|c|c|c|c|c|c|}
\hline \multirow[b]{2}{*}{ Weeks } & \multicolumn{4}{|c|}{ Clone } & \multirow[b]{2}{*}{ Overall } \\
\hline & $\mathrm{D}$ & $\mathrm{H}$ & I & $\mathrm{J}$ & \\
\hline \multicolumn{6}{|c|}{ Mean root area $\left(\mathrm{cm}^{2}\right)$} \\
\hline 5 & $4.38^{y}$ & 20.07 & 2.78 & 12.42 & $9.91^{\mathrm{x}}$ \\
\hline 6 & 10.82 & 22.95 & 2.11 & 20.60 & 14.12 \\
\hline 7 & 21.96 & 26.34 & 8.03 & 25.54 & 20.47 \\
\hline 8 & 15.54 & 28.34 & 5.41 & 31.38 & 20.17 \\
\hline 9 & 14.96 & 38.66 & 9.44 & 29.38 & 23.11 \\
\hline Significance & $\mathrm{Q}^{* * * *}$ & $\mathrm{~L}^{* * * *}$ & $\mathrm{~L}^{* * * *}$ & $\mathrm{~L}^{* * * *}$ & $\mathrm{~L}^{* * * *}$ \\
\hline \multicolumn{6}{|c|}{ Mean rhizome number } \\
\hline 5 & $0.00^{y}$ & 0.00 & 0.00 & 0.00 & $0.00^{x}$ \\
\hline 6 & 0.04 & 0.00 & 0.09 & 0.04 & 0.04 \\
\hline 7 & 0.29 & 0.11 & 0.09 & 0.02 & 0.13 \\
\hline 8 & 0.16 & 0.40 & 0.02 & 0.02 & 0.15 \\
\hline 9 & 0.07 & 0.42 & 0.04 & 0.09 & 0.16 \\
\hline Significance & $\mathrm{Q}^{* *}$ & $\mathrm{~L}^{* * *}$ & NS & NS & $\mathrm{L}^{* * *}$ \\
\hline \multicolumn{6}{|c|}{ Mean rhizome length $(\mathrm{cm})$} \\
\hline 5 & $0.00^{\mathrm{w}}$ & 0.00 & 0.00 & 0.00 & $0.00^{v}$ \\
\hline 6 & 1.75 & 4.00 & 0.00 & 3.50 & 3.00 \\
\hline 7 & 2.50 & 3.30 & 1.95 & 2.00 & 2.64 \\
\hline 8 & 3.08 & 3.88 & 1.50 & 6.50 & 3.69 \\
\hline 9 & 3.50 & 6.17 & 2.75 & 6.50 & 5.58 \\
\hline Significance & $\mathrm{L}^{* * * *}$ & $\mathrm{~L}^{* * * *}$ & $\mathrm{~L}^{* * * *}$ & $\mathrm{~L}^{* * * *}$ & $\mathrm{~L}^{* * *}$ \\
\hline
\end{tabular}

${ }^{z}$ Cuttings assessed after $5,6,7,8$, or 9 weeks under mist, respectively.

${ }^{y}$ All values are means of three replicates; 15 cuttings per replicate.

${ }^{x}$ Values are means of four clones, 45 cuttings per clone.

${ }^{w}$ Overall mean of cuttings that produced rhizomes; number of observations ranged from $0-24$.

Mean of cuttings that produced rhizomes; number of observations ranged from $0-16$.

NS, ${ }^{* *},{ }^{* * *}$ Nonsignificant or significant $P \leq 0.05$ or 0.01 , respectively; $\mathrm{L}=$ linear; $\mathrm{Q}=$ quadratic.

Table 5. Mean number of shoots produced by bunchberry cuttings as affected by rooting duration. (October assessment) ${ }^{\mathrm{z}}$.

\begin{tabular}{lrrrrr}
\hline \multirow{2}{*}{ Weeks } & \multicolumn{5}{c}{ Clone } \\
\cline { 2 - 5 } \\
\cline { 2 - 5 } $\mathrm{D}^{\mathrm{y}}$ & $\mathrm{H}$ & $\mathrm{I}$ & $\mathrm{J}$ & Overall $^{\mathrm{x}}$ \\
\hline 5 & 2.77 & 1.85 & 0.85 & 2.23 & 1.92 \\
6 & 3.92 & 1.62 & 0.69 & 2.23 & 2.12 \\
7 & 1.54 & 1.85 & 1.15 & 1.39 & 1.48 \\
8 & 1.39 & 1.77 & 1.08 & 1.08 & 1.33 \\
9 & 2.00 & 2.39 & 1.23 & 1.15 & 1.69 \\
Significance & $\mathrm{L}^{* *}$ & $\mathrm{NS}$ & $\mathrm{L}^{* *}$ & $\mathrm{~L}^{* *}$ & $\mathrm{~L}^{*}$ \\
& $\mathrm{C}^{* *}$ & --- & --- & --- & $\mathrm{C}^{*}$ \\
\hline
\end{tabular}

$\overline{{ }^{2} \text { Cuttings rooted } 5,6,7,8 \text {, and } 9 \text { weeks were grown on greenhouse bench for }}$ $13,12,11,10$, and 9 weeks, respectively. Significant clone $\times$ rooting duration interaction for these response variables, $P \leq 0.05$.

y Mean of 13 cuttings.

${ }^{\mathrm{x}}$ All values are means of four clones; 13 cuttings per clone.

NS, ${ }^{* *}, * * *$ Nonsignificant or significant at $\mathrm{P} \leq 0.05$ or 0.001 , respectively; $\mathrm{L}=$ linear, $\mathrm{C}=$ cubic

variables measured at both assessment times (before transplanting and at the end of Oct.), producing fewer roots and rhizomes than cuttings from other clones tested. Conversely, clone $\mathrm{H}$ consistently performed well for all variables measured. This suggests that clones being considered for commercial production should be assessed not only for ornamental attributes, but also for success of propagation since there is obviously clonal variability for this trait. It was also apparent, from the various and often conflicting responses of clones to rooting duration, that clones differed in the length of time needed for successful rooting and rhizome formation. Based on the Oct. assessment, longer rooting durations ( 7 weeks or longer) produced greater root systems overall, while shorter rooting durations (5 to 6 weeks) resulted in more numerous shoots and rhizomes by the end of the season. Formation of rhizomes during rooting in the mist enclosure was not necessary for successful rhizome and shoot formation, since none of the cuttings from the 5- and 6-week rooting durations possessed rhizomes at time of transplant. However, these overall results (averaged across clones) were mostly due to the strong response of clone $\mathrm{H}$ to the treatments; this again stresses the importance of considering clonal variability when making general recommendations for propagation of bunchberry.

The finding that cuttings rooted 5-6 weeks 
Table 6. Mean rhizome length, mean total shoot weight, mean rootball size, and mean total rhizome weight of rooted cuttings as affected by bunchberry clone, averaged across rooting duration treatments (October assessment). ${ }^{\mathrm{z}}$

\begin{tabular}{lcccc}
\hline Clone & $\begin{array}{c}\text { Mean rhizome } \\
\text { length } \\
(\mathrm{cm})\end{array}$ & $\begin{array}{c}\text { Mean total } \\
\text { shoot } \mathrm{wt}^{\mathrm{y}} \\
(\mathrm{g})\end{array}$ & $\begin{array}{c}\text { Mean root- } \\
\text { ball size } \\
\left(\mathrm{cm}^{2}\right)\end{array}$ & $\begin{array}{c}\text { Rhizome } \mathrm{wt} \\
\text { per cutting } \\
(\mathrm{g})\end{array}$ \\
\hline $\mathrm{H}$ & $15.42 \mathrm{a}^{\mathrm{x}}$ & $0.48 \mathrm{a}^{\mathrm{w}}$ & $81.58 \mathrm{a}$ & $0.051 \mathrm{a}$ \\
$\mathrm{J}$ & $5.61 \mathrm{bc}$ & $0.28 \mathrm{~b}$ & $67.13 \mathrm{~b}$ & $0.007 \mathrm{c}$ \\
$\mathrm{D}$ & $8.11 \mathrm{~b}$ & $0.31 \mathrm{~b}$ & $74.83 \mathrm{ab}$ & $0.022 \mathrm{~b}$ \\
$\mathrm{I}$ & $1.30 \mathrm{c}$ & $0.13 \mathrm{c}$ & $36.24 \mathrm{c}$ & $0.003 \mathrm{c}$ \\
\hline
\end{tabular}

${ }^{2}$ Data taken 18 weeks after cuttings were stuck. No significant clone $\times$ rooting duration interaction for these response variables, $P \leq 0.05$.

${ }^{y}$ Values are means of five rooting durations; 13 cuttings per rooting duration.

${ }^{x}$ Mean separation within columns by Duncan's multiple range test, $P \leq 0.05$.

wean shoot weight per pot.

Table 7. Effect of rooting duration, averaged across clones, on rootball size, mean rhizome weight per cutting, and average rhizome weight of bunchberry cuttings (October assessment) ${ }^{2}$.

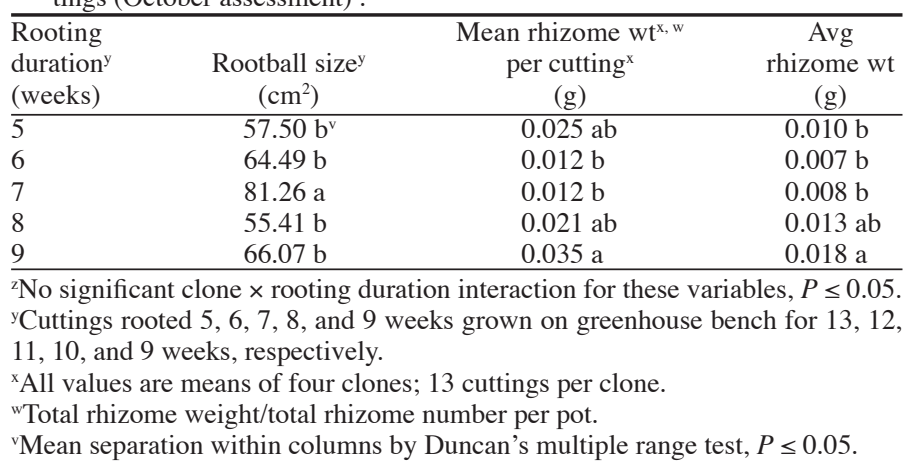

and possessing no rhizomes at transplant produced the most rhizomes and shoots by the end of the season seems to conflict with the results of the propagation time study; this study indicated that cuttings lacking rhizomes at transplant time generally produced fewer shoots by the end of the season than those with rhizomes. This discrepancy may be explained by rooting duration. In the propagation time study, cuttings were allowed to root 10 weeks because it was believed that formation of rhizomes prior to transplant would be advantageous to long-term growth. After ten weeks, most cuttings capable of producing rhizomes had done so by the time of transplant, explaining why the cuttings in classes 3 and 4 produced few if any new shoots. In the rooting duration study, cuttings kept under mist for 5-6 weeks had ample time to form root systems, but had not yet initiated rhizome growth when they were removed and transplanted. The results of this study indicate that cuttings removed from the mist enclosure earlier, and consequently allowed more time for growth in the greenhouse, produced a greater number of rhizomes and shoots. This may indicate that while the conditions in the mist enclosure are ideal for rooting, rhizome and shoot production are favored by exposure to normal greenhouse conditions.

Rhizome formation is essential to overwinter survival of bunchberry rooted cuttings, and maximization of rhizome number and dry weight should be the goal of successful propagation. Rhizomes are the overwintering portion of the bunchberry plant, so if rooted cuttings fail to produce adequate rhizome systems during the first growing season, the plant will not reinitiate growth the following spring. The results of the rooting duration study seem to indicate that cuttings rooted for shorter durations, with the concomitant longer period of growth time on the greenhouse bench, generally produce the most rhizomes by the end of the season. Thus shorter rooting durations are recommended for successful propagation of bunchberry.

In summary, stem cutting propagation has potential for more widespread use in the commercial propagation of bunchberry. The results of our studies suggest that shoot growth and rhizome spread of bunchberry can be maximized during the first season if three-node cuttings are taken from greenhouse-forced material in early spring, treated with $3000 \mathrm{mg} \cdot \mathrm{L}^{-1} \mathrm{~K}$-IBA in water as a 7-s dip, and rooted in a polyethylene enclosure for 5 to 6 weeks.

\section{Literature Cited}

Alaback, P.B. 1984. Plant succession following logging in the sitka spruce-western hemlock forests of southeast Alaska: Implications for management. Pacific Northwest Forested Range Expt. Sta.: General Tech. Rpt. October PNW-173.

Dirr, M.A. 1990. Manual of woody landscape plants. Stipes, Champaign, Ill.

Dirr, M.A. and C.W. Heuser. 1987. The reference manual of woody plant propagation: From seed to tissue culture. Varsity Press, Athens, Ga.

Hall, I.V. and J.D. Sibley. 1976. The biology of Canadian weeds. 20. Cornus canadensis L. Can. J. Plant Sci. 56:885-892.

Haynes, J.G., P. Cappiello, and J. Smagula. 1998. Propagation and production of bunchberry (Cornus canadensis L.). Comb. Proc. Int. Plant Prop. Soc. 47:507-512.

Witt, H.H. 1987. Cornus canadensis-aus dem Schattendasein. GB I GW Bluhende Topfpflanzen. August: 297-298. 